\title{
Influência da heteromorfia de sementes na morfometria, germinação, vigor e caracterização morfológica de plântulas de Parahancornia fasciculata (Poir) Benoist
} - 'Amapá Amargoso'

\author{
Influence of seed heteromorphy on morphometry, germination, vigor and morphological \\ characterization of Parahancornia fasciculata (Poir) Benoist - 'Amapá Amargoso' \\ Influencia de la heteromorfia de semillas en la morfometría, germinación, vigor y caracterización \\ morfológica de plántulas de Parahancornia fasciculata (Poir) Benoist - 'Amapá Amargoso'
}

\author{
Joyce Ananda Paixão Duarte \\ ORCID: https://orcid.org/0000-0002-4953-7840 \\ Universidade Federal Rural da Amazônia, Brasil \\ E-mail: joyceananda@yahoo.com.br \\ Luiz Fernandes Silva Dionisio \\ ORCID: https://orcid.org/0000-0002-4324-2742 \\ Universidade do Estado do Pará, Brasil \\ E-mail: fernandesluiz03@gmail.com \\ Gabriele do Nascimento Furtado \\ ORCID: https://orcid.org/0000-0002-6913-1848 \\ Universidade do Estado do Pará, Brasil \\ E-mail: gabriele.engflor@gmail.com \\ Etiane de Souza Silva \\ ORCID: https://orcid.org/0000-0002-6725-0982 \\ Universidade Federal do Pará, Brasil \\ E-mail: etianesaraff@hotmail.com
}

\begin{abstract}
Resumo
Parahancornia fasciculata (Poir) Benoist, conhecida popularmente como amapá amargoso, é uma espécie importante na medicina popular e farmacológica por conta do látex de seu tronco, chamado de "leite do amapá". Porém os estudos sobre a tecnologia de sementes dessa espécie ainda são incipientes. O objetivo do trabalho foi do avaliar a influência da cor do tegumento (heteromorfia) na morfometria, germinação, vigor de sementes e produção de mudas de $P$. fasciculata de forma a definir as sementes que apresentam maior vigor e o substrato que favorece a germinação. Para o teste de germinação, o delineamento experimental foi inteiramente casualizado em fatorial $2 \times 4$ em quatro repetições, sendo dois tipos de cor de semente (amarela e marrom) e quatro tipos de substratos (areia, vermiculita, areia e vermiculita 1:1, e areia e vermiculita 2:1). As sementes marrons tiveram o comprimento, largura e massa da matéria fresca maiores em relação as sementes amarelas, o que indica que as sementes marrons apresentam maior nível de maturação, além de terem tido maiores porcentagens de germinação sob vermiculita, o que relaciona o vigor da semente marrom sendo favorecido sob a vermiculita. A morfologia da germinação é do tipo epígea, os cotilédones são foliáceos e fotossintetizantes, a raiz é axial e pivotante, hipocótilo de consistência herbácea, protófilos alternos verdes e venação broquidódroma. Os resultados deste estudo indicam a importância do uso seletivo de sementes a partir da coloração do tegumento para garantir a qualidade e o sucesso na produção de mudas.
\end{abstract}

Palavras-chave: Amapá amargoso; Planta medicinal; Leite do amapá; Tecnologia de sementes; Heteromorfismo.

\begin{abstract}
Parahancornia fasciculata (Poir) Benoist, popularly known as 'amapá amargoso', is an important species in popular and pharmacological medicine due to the latex of its trunk, called 'leite do amapá. However, studies on seed technology of this species are still incipient. The objective of this work was to evaluate the influence of the tegument color (heteromorphism) on the morphometry, germination, seed vigor and seedling production of $P$. fasciculata in order to define the seeds that present greater vigor and the substrate that favors germination. For the germination test, the experimental design was completely randomized in a 2x4 factorial in four replications, two types of seed color (yellow and brown) and four types of substrates (sand, vermiculite, sand and vermiculite 1: 1, and sand and vermiculite 2: 1). The brown seeds had a longer length, width and mass of fresh matter compared to yellow seeds, which indicates that brown seeds have a higher level of maturation, in addition to having higher germination
\end{abstract}


percentages under vermiculite, which relates the vigor of the brown seed being favored under the vermiculite. The germination morphology is of the epigeal type, the cotyledons are foliaceous and photosynthetic, the root is axial and pivoting, a hypocotyl of herbaceous consistency, alternating green protophils and broquidodroma venation. The results of this study indicate the importance of the selective use of seeds based on the color of the seed coat to ensure quality and success in the production of seedlings.

Keywords: Amapá amargoso; Medicinal plant; Leite do amapá; Seed technology; Heteromorphism.

\section{Resumen}

Parahancornia fasciculata (Poir) Benoist, conocido popularmente como 'amapá amargoso', es una especie importante en la medicina popular y farmacológica debido al látex de su tronco, llamado "leche de amapá". Sin embargo, los estudios sobre tecnología de semillas de esta especie aún son incipientes. El objetivo de este trabajo fue evaluar la influencia del color del tegumento (heteromorfismo) en la morfometría, germinación, vigor de semilla y producción de plántula de $P$. fasciculata con el fin de definir las semillas que presentan mayor vigor y el sustrato que favorece la germinación. Para la prueba de germinación, el diseño experimental fue completamente al azar en un factorial $2 \times 4$ en cuatro repeticiones, dos tipos de color de semilla (amarillo y marrón) y cuatro tipos de sustratos (arena, vermiculita, arena y vermiculita 1: 1, y arena y vermiculita 2: 1). Las semillas marrones tuvieron mayor longitud, ancho y masa de materia fresca en comparación con las semillas amarillas, lo que indica que las semillas marrones tienen un mayor nivel de maduración, además de tener mayores porcentajes de germinación bajo vermiculita, lo que relaciona el vigor de la la semilla marrón se ve favorecida bajo la vermiculita. La morfología germinativa es de tipo epigeal, los cotiledones son foliáceos y fotosintéticos, la raíz es axial y pivotante, un hipocótilo de consistencia herbácea, alternancia de protófilos verdes y venación de broquidodroma. Los resultados de este estudio indican la importancia del uso selectivo de semillas en función del color de la cubierta de la semilla para asegurar la calidad y el éxito en la producción de plántulas.

Palabras clave: Amapá amargo; Planta medicinal; Leche de amapá; Tecnología de semillas; Heteromorfismo.

\section{Introdução}

Parahancornia fasciculata (Poir) Benoist é uma espécie da família Apocynaceae conhecida popularmente como ‘amapá amargoso' ou 'amapazeiro' (Mendonça et al., 2011). É uma das espécies mais importantes no mercado amazônico por conta do látex extraído de seu tronco, também chamado de "leite do amapá", utilizado tradicionalmente no tratamento de enfermidades das vias respiratórias e gástrica (Silva et al., 2011; Santos et al., 2013), além do uso como biopesticidas (Mendonça et al., 2011) e grandes utilidades nas áreas químicas e farmacológicas (Matta, 2003; Santos et al., 2013). O amapá amargoso tem relevante importância econômica e social às comunidades tradicionais da Amazônia, porém pouco se sabe sobre as características morfológicas das sementes, frutos e plântulas, bem como a qualidade fisiológica das sementes quando se trata da heteromorfia que a espécie apresenta quanto a coloração das sementes.

O heteromorfismo de sementes é um fenômeno no qual uma planta produz dois ou mais tipos distintos de sementes no mesmo fruto e pode influenciar o desenvolvimento da planta em diferentes estágios (Santos e Aguiar, 2005; Yuyama e Silva Filho, 2003). A heteromorfia é geralmente considerada como uma estratégia adaptativa das espécies para sobreviver em ambientes com altos níveis de perturbações antrópicas (Liu, et al., 2018). Essa característica, observada também em outras espécies vegetais, pode ser utilizado como um índice morfológico visual para informar sobre a maturidade e potencial fisiológico (Soares et al., 2016). O potencial fisiológico traz informações acerca da viabilidade quanto a germinação e vigor de sementes que influencia muito no desempenho da produção de mudas de qualidade (Marcos Filho, 2015, Medeiros et al., 2019). No entanto, são necessários testes de germinação para avaliar a qualidade fisiológica das sementes e conhecer o potencial de germinação destas para subsidiar informações consistentes sobre a propagação e produção de mudas de qualidade (Silva et al., 2016).

O estudo das características morfológicas associadas à ecologia das espécies nativas possibilita um melhor entendimento da funcionalidade dessas estruturas nos ecossistemas, contribuindo para o desenvolvimento de programas de conservação e restauração ambiental (Cosmo et al., 2017). A propagação e conservação de espécies tradicionais da floresta amazônica exige domínio das técnicas de tecnologia de sementes, germinação e propagação, especialmente no que diz respeito as análises biométricas que são importantes ferramentas para descrever as características morfológicas, identificando de forma 
única cada indivíduo e identificar variações existentes entre espécies de mesmo género, através de caracterização morfológica e de adaptação de indivíduos (Duarte, et al., 2015; Melo et al., 2018).

Outro fator que influência na germinação e produção de mudas é o tipo de substrato utilizado quanto se trata de sua estrutura, aeração, capacidade de retenção de água, grau de infestação de patógenos que podem favorecer ou prejudicar a germinação das sementes (Soares et al., 2016). Ao escolher um substrato, alguns aspectos devem ser considerados, como o tamanho da semente, a exigência com relação à água e à luz, a facilidade que ele oferece durante a instalação, a realização das contagens e a avaliação das plântulas (Brasil, 2009a).

Desta forma, este trabalho teve por objetivo avaliar a influência da heteromorfia, a partir da coloração do tegumento das sementes (marrom e amarela), na morfometria, germinação e vigor de plântulas de forma a definir o tipo de sementes e o substrato que mais favorece a germinação e o desenvolvimento das plântulas de $P$. fasciculata.

\section{Metodologia}

Foram coletados frutos maduros, após a ocorrência da dispersão natural em matrizes de $P$. fasciculata localizadas no Bosque Rodrigues Alves - Jardim Botânico da Amazônia (BRAJBA). O BRAJBA é um fragmento com área de 15 ha composto por floresta ombrófila densa não aluvial nativa situado no centro da cidade de Belém-PA (1 $25^{\prime} 48,7^{\prime \prime} \mathrm{S}$ 482’24,71'” W) (Figura 1).

Figura 1. Área de coleta de sementes em matrizes de Parahancornia fasciculata (Poir) Benoist no Bosque Rodrigues Alves Jardim Botânico da Amazônia no município de Belém-Pará.

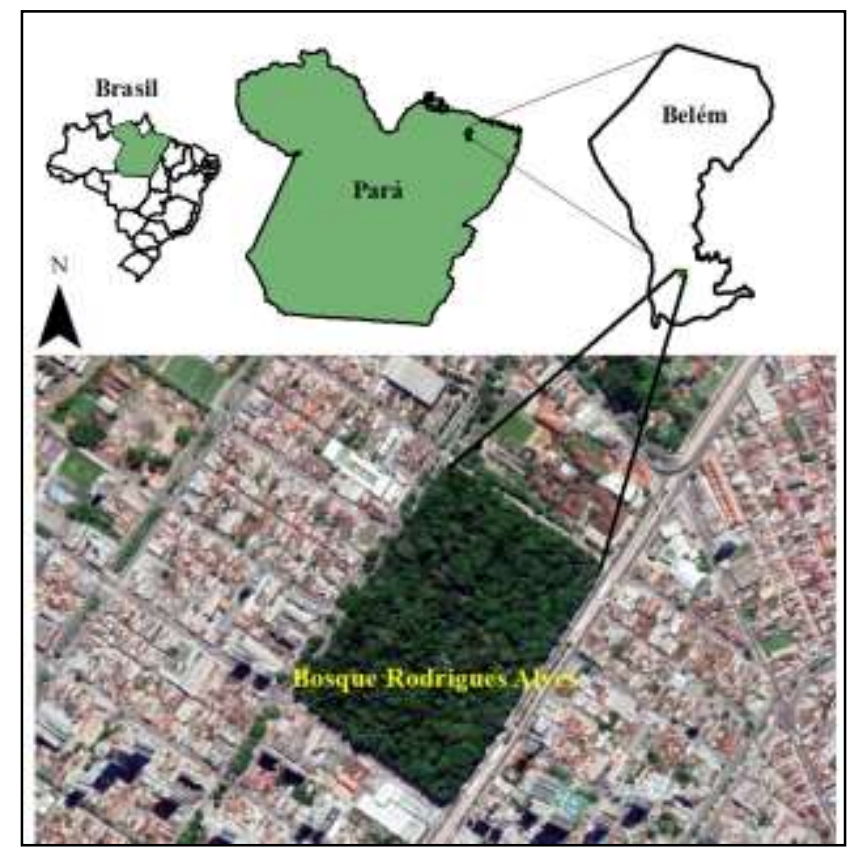

Fonte: Duarte, J. A. P. (2021).

Após a coleta, os frutos foram beneficiados manualmente, a partir da remoção da polpa, e as sementes foram separadas de acordo com a coloração do tegumento em amarelas e marrons de maneira visual. Para a caracterização biométrica, foram utilizados 50 frutos e 200 sementes obtendo as seguintes variáveis: comprimento, largura, espessura do epicarpo (casca), espessura da semente, massa da matéria fresca do epicarpo e da polpa e massa da semente de acordo com a coloração. Foi avaliado o número de sementes amarelas e marrons por fruto, a contagem do número de semente por 
quilograma e o peso de 1000 sementes de acordo com a metodologia de Brasil (2009a). As medições foram feitas com auxílio de um paquímetro digital com precisão de $0,01 \mathrm{~mm}$ e balança digital de precisão.

Para avaliar a heteromorfia do tegumento, foi calculado o número de sementes amarelas e marrons por fruto, a contagem do número de semente por quilograma e o peso de 1000 sementes utilizando seis repetições (Brasil, 2009a). Para quantificar o teor de umidade das sementes foi utilizada uma amostragem de quatro repetições de 30 sementes de cada coloração (amarelas e marrons), foram previamente pesadas e após colocadas na estufa a $200^{\circ} \mathrm{C}$ por 24 horas. Para o teste de dessecação foi utilizado quatro repetições de 25 sementes por coloração, após as sementes atingirem $10 \%$ de umidade, foi realizado o teste de germinação de acordo com Brasil (2009a). A classificação das sementes quanto ao comportamento em relação à perda de água foi conforme Hong E Ellis (1996).

Para avaliar os efeitos da heteromorfia do tegumento e do substrato na germinação de $P$. fasciculata foi feito o delineamento experimental inteiramente casualizado em fatorial $2 \times 4$ com quatro repetições de 25 sementes, sendo dois tipos de coloração das sementes (amarela e marrom) e quatro tipos de substratos (areia, vermiculita, areia e vermiculita 1:1, e areia e vermiculita 2:1). A semeadura foi em caixas plásticas do tipo gerbox e colocadas em câmeras de germinação do tipo Mangelsdorf a temperatura constante de $25^{\circ} \mathrm{C}$.

A germinação foi monitorada diariamente, considerando o início a partir da emissão da radícula. As variáveis avaliadas foram: porcentagem de germinação (G\%), tempo médio de germinação (TMG) e índice de velocidade de germinação (IVG), esta última foi calculada segundo Popinigis (1977).

Em relação a caracterização morfológica dos frutos e sementes de $P$. fasciculata foram considerados os seguintes aspectos: tipo, forma, cor, textura, consistência da estrutura interna e externa do pericarpo e dos tegumentos, deiscência e outras estruturas presentes (Vidal \& Vidal, 1995; Barroso et al., 1999; Brasil, 2009b). As avaliações das fases de desenvolvimento das plântulas foram utilizadas 50 plântulas em fases sequências de desenvolvimento até o $50^{\circ}$ dia, quando já apresentavam todas as estruturas essenciais como: raiz primária, raiz secundária, colo, hipocótilo, cotilédones, epicótilo e protófilos aberto (Albuquerque, 1993; Vidal \& Vidal, 2003; Brasil, 2009b). As observações foram realizadas com a olho nu e com o auxílio de uma lupa manual.

A biometria dos frutos e das sementes foram analisados pela estatística descritiva e pelo coeficiente de variação (CV), de acordo com Gomes \& Garcia (2002), onde consideram baixo quando CV $<10 \%$ (homocedasticidade), médio quando $10 \%<\mathrm{CV}<20 \%$, alto quando $20 \%<\mathrm{CV}<30 \%$ e muito alto, quando $\mathrm{CV}>30 \%$ (heterocedasticidade).

Os dados de germinação foram avaliados pela análise estatística univariada, submetidos a testes de normalidade e homogeneidade pelo teste de Bartllet e comparados pelo Teste Student-Newman-Keuls (SNK) a 5\% de probabilidade. Todas as análises foram realizadas por meio do programa $\mathrm{SAEG}{ }^{\circledR}$.

\section{Resultados e Discussão}

Os frutos de $P$. fasciculata se caracterizam por serem carnosos, indeiscentes, com epicarpo atrovioláceo quando maturo, do tipo simples, bacóides, globosos e elipsoide (Figura 2A; Figura 2B), polispérmico, variando de 2 a 46 sementes (Figura 2C). Possui a cavidade preenchida com polpa sucoso-gelatinosa avermelhada de origem placentar com sabor e cheiro adocicado (Figura 2C; Figura 2D), o que pode ser uma das estratégias que atraem os principais dispersores desta espécie, como macacos, cutias e outros mamíferos (Morais, et al., 1995). 
Figura 2. Caracterização do fruto e sementes de Parahancornia fasciculata (Poir) Benoist na posição lateral (A), posição frontal (B), interior do fruto com polpa (C), sem polpa (D) e semente marrom (E) e amarela (F).

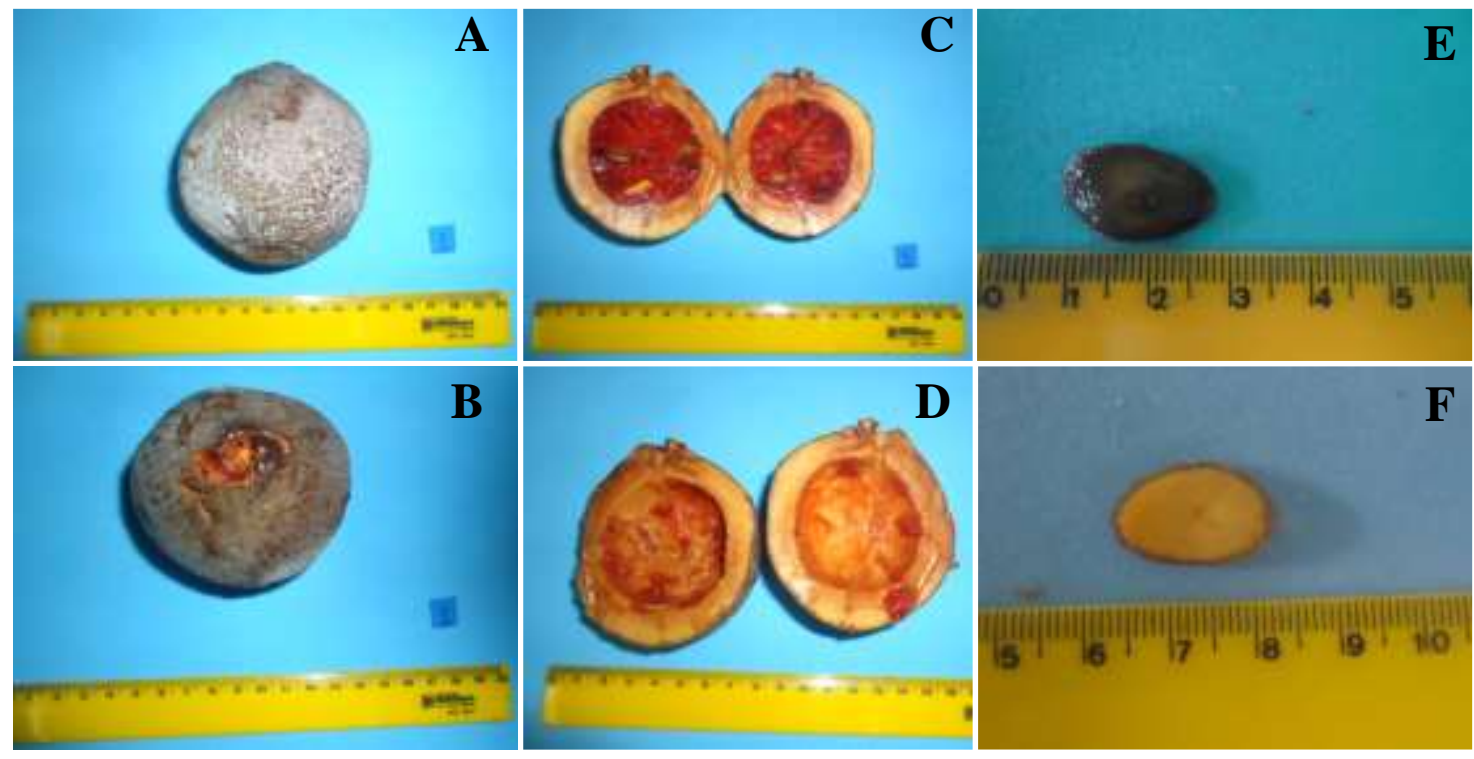

Fonte: Duarte, J. A. P. (2021).

As sementes são unitegumentada, forma do tipo ovóide-achatada, lisa, revestida de substância mucilaginosa, que se torna gelatinosa em presença de água, a testa apresenta variações de coloração de amarelo a marrom (Figura 2E; Figura 2F). O hilo é do tipo ventral e ovalado. A semente madura de $P$. fasciculata é envolta pela testa repleta de saliências e reentrâncias, com compostos fenólicos e mucilagem na exotesta, que pode ter a função de proteção, regulação e absorção de água, além de ser uma estratégia da planta em manter uma concentração suficiente de água ao redor da semente assim aumentar o grau de germinação (Alves, et al., 2012).

As características biométricas físicas do fruto de $P$. fasciculata evidenciaram uma considerável amplitude e variabilidade em relação ao comprimento, largura, espessura do epicarpo, massa da matéria fresca do pericarpo, assim como no número de sementes de acordo com a coloração presentes no mesmo fruto (Tabela 1). Estas variáveis denotam que a espécie tem alta heterodasticidade $(\mathrm{CV}>30 \%)$, ou seja, um conjunto de dados bastante heterogêneo. Essas grandes variações das características biométricas podem estar relacionadas às grandes variações ambientais em que as matrizes estão localizadas, num fragmento florestal no meio urbano e por serem matrizes remanescentes de floresta nativa, tais fatores podem grande diversidade genotípica das populações o que resulta em diferentes características fenotípicas para a espécie (Maciel, et al., 2007; Oliveira-Bento, et al., 2013; Lau, et al., 2020). 
Tabela 1. Estatística descritiva das características físicas dos frutos de Parahancornia fasciculata (Poir) Benoist.

\begin{tabular}{lcccccc}
\hline \multirow{2}{*}{ Variáveis (Fruto) } & \multicolumn{7}{c}{ Medidas estatísticas } \\
\cline { 2 - 7 } & Mínimo & Máximo & Média & Mediana & Desv.Pad. & CV (\%) \\
\hline Comprimento (mm) & 38,5 & 98,7 & 66,8 & 64,7 & 11,8 & 17,7 \\
Largura (mm) & 39,3 & 89,0 & 69,5 & 69,1 & 10,8 & 15,6 \\
Espessura do epicarpo (mm) & 7,4 & 19,0 & 12,1 & 12,4 & 2,7 & 22,4 \\
Massa da matéria fresca (epicarpo) (g) & 25,8 & 262,1 & 131,1 & 117,3 & 55,1 & 42,0 \\
Massa da matéria fresca (polpa) (g) & 4,0 & 123,6 & 41,6 & 33,1 & 27,6 & 66,2 \\
Massa da matéria fresca total (g) & 29,9 & 342,1 & 172,7 & 160,0 & 75,0 & 43,4 \\
$\mathrm{~N}^{\circ}$ total de sementes marrons por fruto & 2,0 & 28,0 & 9,9 & 8,0 & 6,5 & 65,8 \\
$\mathrm{~N}^{\circ}$ total de sementes amarelas por fruto & 0,0 & 18,0 & 4,8 & 4,0 & 3,7 & 76,4 \\
$\mathrm{~N}^{\circ}$ total de sementes por fruto & 2,0 & 46,0 & 14,7 & 12,5 & 9,2 & 62,3
\end{tabular}

Nota: Desv.Pad. - Desvio Padrão; CV - Coeficiente de variação. Fonte: Autores (2021).

Foi observado que as médias de comprimento, largura e massa da matéria fresca foram maiores nas sementes marrons em relação as sementes de cor amarela, o que implicou diretamente no maior número de sementes amarelas por quilograma com uma diferença de 120 sementes em relação às marrons (Tabela 2). O tamanho e o peso das sementes podem ser considerados um indicativo de sua qualidade fisiológica, sementes mais leves, normalmente, apresentam menor desempenho do que as mais pesadas, tanto na germinação como no crescimento inicial das plantas, devido à quantidade de reservas acumuladas e na formação do embrião (Barbedo \& Marcos-Filho, 1998). Em outras espécies também foi observado que as sementes marrons tiveram suas dimensões maiores em relação às sementes amareladas ou esverdeadas (Venturi \& Randi, 1997; Yuyama \& Silva-Filho, 2003).

A plasticidade fenotípica de algumas espécies heteromórficas, como as proporções e os números de morfologia de frutos e sementes, tem sido considerada um mecanismo da espécie para lidar com ambientes imprevisíveis (Cao, et al., 2020). Segundo Liu e colaboradores (2018) afirmam que o ambiente no qual a matriz se encontra pode influenciar nas características morfológicas de frutos e sementes, visto que em condições de altos níveis de estresse as árvores podem apresentar sinais que são reproduzidos às próximas gerações a partir dos diferentes fenótipos, devido aos efeitos transgeracionais. As matrizes de $P$. fasciculata estão localizadas no Jardim Botânico da Amazônia, que são fragmentos florestais com vegetação remanescente de mata de terra firme, que anos com o crescimento populacional estas áreas foram sendo cercadas por casas, edifícios e comércios, e encontram-se ilhadas pela zona urbana e com bioindicadoes de altos níveis de poluição (Lisboa \& Ilkiu-Borges, 1995; Maciel, et al., 2007). 
Tabela 2. Estatística descritiva das características físicas das sementes amarelas e marrons de Parahancornia fasciculata (Poir) Benoist.

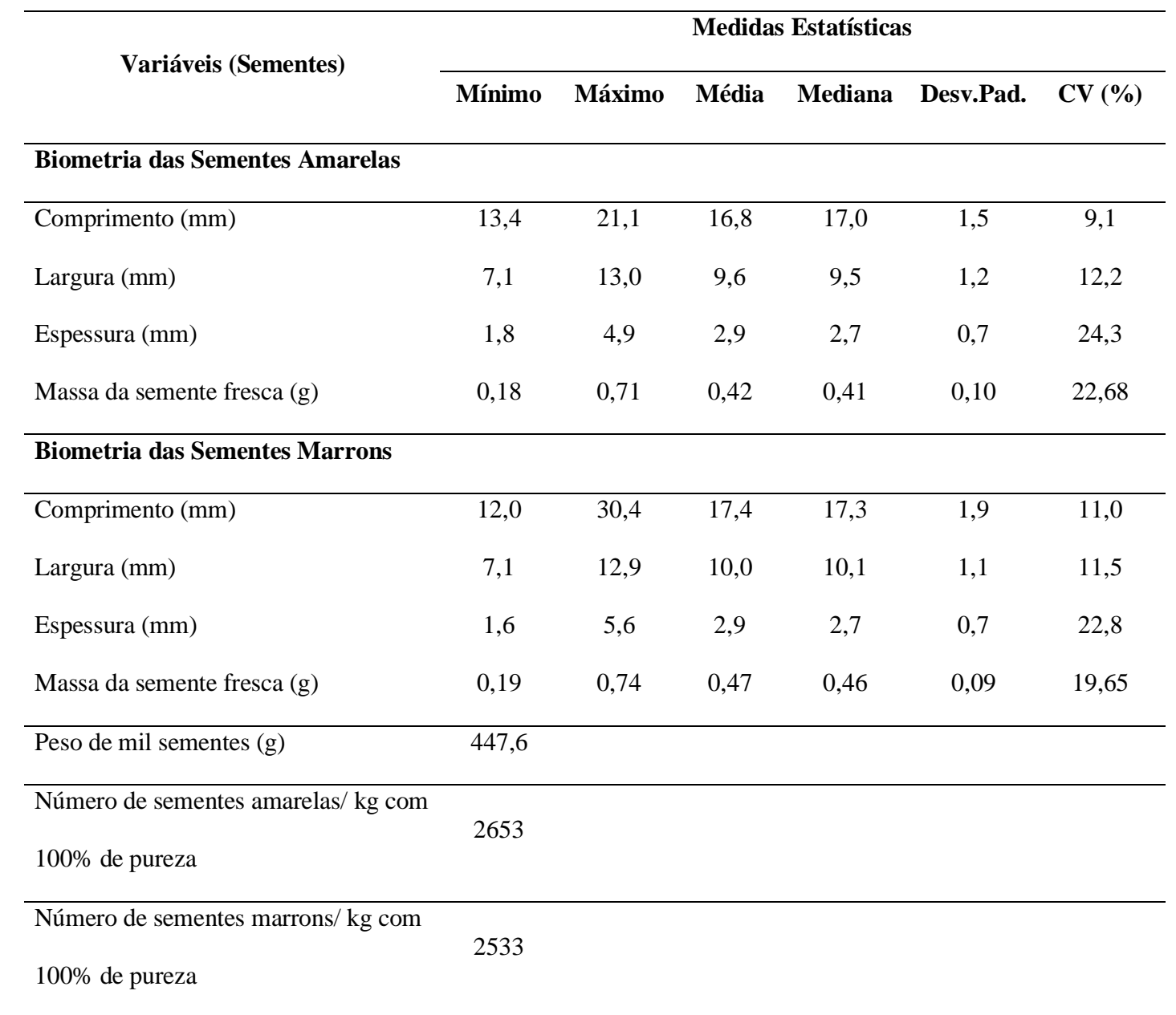

Desv.Pad. - Desvio Padrão; CV - Coeficiente de variação. Fonte: Autores (2021).

O teor de umidade para as sementes amarelas foi de 57,8\% e das sementes marrons de 57,32\%. Apesar da pequena diferença no teor de umidade entre a coloração das sementes, nota-se que as sementes amarelas ainda estão no início do processo de maturação devido ao menor teor de água que reduz gradualmente nos estádios iniciais de formação das sementes, isso se deve a translocação do material fotossintetizado nos tecidos de reserva (Barbedo \& Marcos-Filho, 1998; Carvalho \& Nakagawa, 2000). De maneira geral, estudos mostram que sementes com alto teor de umidade, acima 40\%, apresentam altas taxas de metabolismo e respiração e não suportam dessecação a níveis abaixo de 12 a $31 \%$ (Barbedo \& Marcos-Filho, 1998) como ocorreu em outras espécies pertencentes a família Apocynaceae (Salomão et al., 2004; Piovesan et al, 2013).

A secagem das sementes de $P$. fasciculata em sílica gel promoveu a redução do teor de água nas sementes amarelas de $57,32 \%$ para $17,67 \%$ e para as sementes marrons de 57,8\% para 15,25\% em apenas três dias. Nesse período de dessecação ocorreu efeito negativo na viabilidade das sementes, pois nenhuma semente germinou, indicando que o comportamento da semente é do tipo recalcitrante, independente da coloração, conforme o protocolo de Hong \& Ellis (1996). Assim, as sementes de $P$. fasciculata não suportam a eleveda redução do teor de água por conta das alterações do sistema metabólico que é necessário para a germinação (Barbedo \& Marcos-Filho, 1998).

A germinação das sementes amarelas e marrons teve início $9^{\circ}$ dia, após a instalação do experimento, com duração total de 36 dias para ambos tipos de sementes (amarelas e marrons), o que evidencia padrão desuniforme para germinação independentemente da cor do tegumento. A germinação foi considerada a partir da emissão da radícula de cor esbranquiçada 
com crescimento no sentido geotrópico positivo. O vigor e desempenho da germinação, a partir dos índices de IVG e TMG, diferiu significativamente ao nível de 5\% para ambos fatores testados (coloração da semente e tipo substrato) (Tabela 3). As sementes marrons sob vermiculita, integral ou em alguma proporção, apresentou melhor desempenho no tempo médio de germinação. A porcentagem de germinação não foi significante ao nível de $5 \%$ de probabilidade para o tipo de substrato, porém diferiu estatisticamente para a coloração da semente, em que sementes marrons apresentaram maiores taxas de germinação em relação às sementes amarelas (Tabela 3). Tais índices demonstram que as sementes marrons apresentam maior nível de maturação em relação às sementes amarelas. A maturação das sementes exerce grande influência na germinação e estas atingem maior qualidade fisiológica quando apresentam maior poder germinativo e de vigor (Soares et al., 2016). Outros estudos que avaliaram o heteromorfismo de sementes identificaram que sementes de coloração amarronzadas apresentaram maior poder germinativo associado a maturação fisiológica (Santos \& Aguiar, 2005; Venturi \& Randi, 1997; Soares, et al., 2016).

Tabela 3. Índice de Velocidade de Germinação (IVG), Tempo Médio de Germinação e Porcentagem de Germinação (G\%) de sementes amarelas e marrons de Parahancornia fasciculata (Poir) Benoist sob diferentes substratos.

\begin{tabular}{|c|c|c|c|c|c|c|}
\hline \multirow{3}{*}{ Substrato } & \multicolumn{2}{|c|}{ IVG } & \multicolumn{2}{|c|}{ TMG } & \multicolumn{2}{|c|}{$\mathbf{G}(\%)$} \\
\hline & \multicolumn{2}{|c|}{ Cor da semente } & \multicolumn{2}{|c|}{ Cor da semente } & \multicolumn{2}{|c|}{ Cor da semente } \\
\hline & Amarela & Marrom & Amarela & Marrom & Amarela & Marrom \\
\hline Areia $(100 \%)$ & $2,5 \mathrm{bB}$ & $2,8 \mathrm{bA}$ & $6,8 \mathrm{bA}$ & $6,2 \mathrm{bA}$ & $71,7 \mathrm{Ab}$ & $91,7 \mathrm{Aa}$ \\
\hline Vermiculita (100\%) & $2,2 \mathrm{bC}$ & $3,5 \mathrm{aA}$ & $6,6 \mathrm{bA}$ & $5,6 \mathrm{bB}$ & $73,3 \mathrm{Ab}$ & $86,7 \mathrm{Aa}$ \\
\hline Areia e vermiculita (1:1) & $3,7 \mathrm{bB}$ & $4,2 \mathrm{aA}$ & $5,4 \mathrm{bB}$ & $4,1 \mathrm{cB}$ & $81,7 \mathrm{Ab}$ & $88,3 \mathrm{Aa}$ \\
\hline Areia e vermiculita $(2: 1)$ & $2,3 \mathrm{bC}$ & $3,2 \mathrm{aA}$ & $7,7 \mathrm{aA}$ & $5,4 \mathrm{bB}$ & $83,3 \mathrm{Ab}$ & $84,8 \mathrm{Aa}$ \\
\hline $\mathrm{CV}(\%)$ & \multicolumn{2}{|c|}{27,5} & \multicolumn{2}{|c|}{21,4} & \multicolumn{2}{|c|}{14,09} \\
\hline
\end{tabular}

Nota: Letra maiúscula: Substrato. Letra minúscula: coloração da semente. Valores seguidos pela mesma letra na coluna não diferem entre si pelo Teste SNK (Student-Newman-Keuls) (p <0,05). CV = coeficiente de variação. Fonte: Autores (2021).

O uso de vermiculita tem sido utilizada com bons resultados para as sementes florestais devido a sua boa capacidade de absorção e retenção de água, podendo absorver até cinco vezes o seu volume em água, também é considerada um bom agente de melhoria das condições físicas e químicas, assim o uso da vermiculita de forma integral ou como parte da composição dos substratos aumenta sua capacidade de retenção de água (Duarte et al., 2015).

A morfologia inicial da germinação de P. fasciculata é epígea, em que os cotilédones ficam acima do substrato. A germinação iniciou com a protrusão da radícula ínfera esbranquiçada e saída na base da semente com embrião do tipo hipocotilar (Figura 3). O tegumento seminal se desprendeu dos cotilédones entre o $10^{\circ}$ a $15^{\circ}$ dia após a germinação com abertura horizontal. Os cotilédones são foliáceo-coriáceos, opostos, oblongos, com ápice arredondado, borda inteira, fotossintetizantes, de coloração verde-clara nos primeiros dias e após o amadurecimento tornam-se verde escuro não se desprendendo do hipocótilo durante toda fase de plântula. Os cotilédones por ser foliáceo e fotossintetizante podem ser também definidos como paracotilédones que caracteriza germinação fanerocotiledonar (Figura 3). 
Figura 3. Morfologia da plântula de Parahancornia fasciculata (Poir) Benoist no $1^{\circ}, 3^{\circ}, 7^{\circ}$ e $25^{\circ}$ de germinação. Sendo: tg $=$ tegumento externo; $\mathrm{rd}=$ radícula; $\mathrm{rp}=$ raiz principal $(\mathrm{A}) ; \mathrm{rs}$ = raiz secundária; $\mathrm{hp}=$ hipocótilo; ep = epicótilo; cd = cotilédone; pt $=$ protófilos.

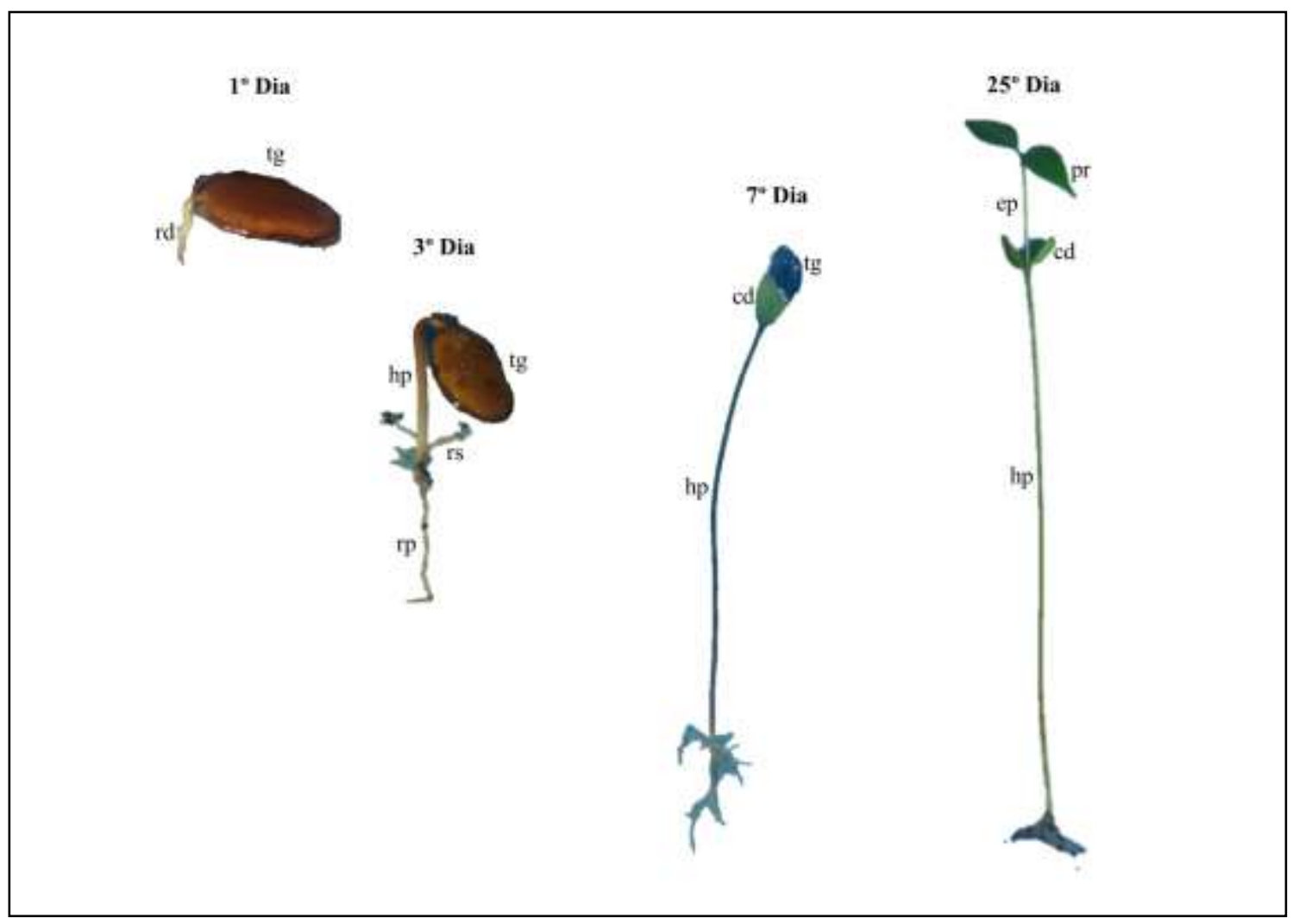

Fonte: Autores (2021).

As plântulas no $25^{\circ}$ dia já apresentam a formação de um par de protófilos alternos verdes, venação broquidódroma, elípticos, curto peciolados, de coloração verde, semelhantes às folhas da planta adulta (Figura 3 ). No $50^{\circ}$ dia de observação, a raiz axial apresentou rápido desenvolvimento com comprimento médio de 61,98 mm de característica amarelo-esbranquiçada, cilíndrica, sinuosa, flexível com base dilatada. A média do diâmetro do colo foi de 1,89 mm. As ramificações secundárias foram evidentes com presença de várias raízes finas curtas, flexíveis e simples. O Hipocótilo é de consistência herbácea, longo, cilíndrico, coloração verde claro, glabro e ereto elevando os cotilédones envolvidos acima do solo e comprimento médio de 235,96 mm. O epicótilo teve o comprimento médio de $82,37 \mathrm{~mm}$ de comprimento no $50^{\circ}$ dia sendo mais curto que o hipocótilo.

As características morfológicas dos frutos da espécie $P$. fasciculata é semelhante com a espécies do mesmo gênero Parahancornia peruviana, também com ocorrência na floresta Amazônica, além da espécie conhecida popularmente como 'amapá-doce' (Brosimum parinarioides ) que também tem propriedades medicinais (Matta, 2003). Na Amazônia, ambas espécies $P$. fasciculata e $B$. parinarioides tem o látex extraído do tronco e são comercializados para uso na medicina popular, podendo ser até confundidos devido as semelhanças (Matta, 2003). Desta forma, o conhecimento das estruturas morfológicas de frutos, sementes e plântulas são ferramentas fundamentais para auxiliar e orientar os extrativistas na identificação correta da espécie. 


\section{Conclusão}

A característica biométrica física dos frutos e sementes apresentou alta heterodasticidade e as sementes marrons tiveram o comprimento, largura e massa da matéria fresca maiores em relação as sementes amarelas, o que indica que as sementes marrons apresentam maior nível de maturação.

A dessecação das sementes teve efeito negativo na germinação das sementes amarelas e marrons caracterizando como recalcitrante independente da cor. Sementes marrons proporcionam maiores porcentagens de germinação sob vermiculita, o que relaciona o vigor da semente marrom associado com o tipo de substrato vermiculita.

A morfologia da germinação é do tipo epígea, os cotilédones são foliáceos e fotossintetizantes, a raiz é axial e pivotante, hipocótilo de consistência herbácea, protófilos alternos verdes e venação broquidódroma.

Os resultados deste estudo indicam a importância do uso seletivo de sementes a partir da coloração do tegumento para garantir a qualidade e o sucesso na produção de mudas. Além disso, o heteromorfismo da semente evidenciado pela coloração de $P$. fasciculata é provavelmente uma estratégia adaptativa da espécie em sobreviver num ambiente com altos níveis de perturbação antrópica.

\section{Referências}

Albuquerque J. M. (1993) Identificação e germinação de sementes amazônicas. Belém: Faculdade de Ciências Agrarias do Para-FCAP, 132 p.

Alves, C. Z., Godoy, A. R., \& Oliveira, N. C. (2012). Efeito da remoção da mucilagem na germinação e vigor de sementes de Hylocereus undatus Haw. Revista Brasileira de Ciências Agrárias 7(4), 586-589. 10.5039/agraria.v7i4a1750

Barbedo, C. J., \& Marcos-Filho, J. (1998). Tolerância à dessecação em sementes. Acta botânica brasílica, 12(2),145-164. https://www.scielo.br/pdf/abb/v12n2/v12n2a05

Barroso, G. M., Morin, M. P., Peixoto, A. L., \& Ichaso, C. L. F. (1999). Frutos e sementes: morfologia aplicada à sistemática de dicotiledôneas. Viçosa: UFV $443 \mathrm{p}$.

Brasila, Ministério da Agricultura e Reforma Agrária. (2009). Regras para análise de sementes. Brasília: Ministério da Agricultura, Pecuária e Abastecimento/ Secretaria de Defesa Agropecuária, 399 p.

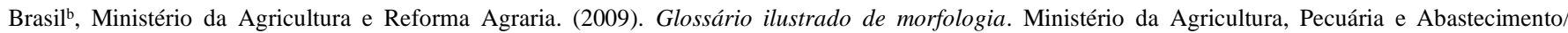
Secretaria de Defesa Agropecuária, 406 p.

Cao, J., Chen, L., Wang, J., Xing, J., Lv, X., Maimaitijiang, T., \& Lan, H. (2020). Effects of genetic and environmental factors on variations of seed heteromorphism in Suaeda aralocaspica, AoB Plants, 12(5), plaa044. https://doi.org/10.1093/aobpla/plaa044

Carvalho, N. M., Nakagawa, J. (2000). Sementes: ciência, tecnologia e produção. (4a ed.), FUNEP, 588 p.

Cosmo, N. L., Gogosz, A. M., Rego, S. S., Nogueira, A. C., \& Kuniyoshi, Y. S. (2017). Morfologia de fruto, semente e plântula, e germinação de sementes de Myrceugenia euosma (O. Berg) D. Legrand (Myrtaceae). Floresta, 47(4): 479-488. 10.5380/rf.v47i4.46933

Duarte, M. M., Milani, J. E. F., Blum, C. T., \&Nogueira, A. C. (2015) Germinação e morfologia de sementes e plântulas de Albizia edwallii(Hoehne) Barneby \& J. W. Grimes. Revista Caatinga, 28(3), 166 - 173. http://dx.doi.org/10.1590/1983-21252015v28n319rc

Gomes, F. P., \& Garcia, C. H. (2002). Estatística aplicada a experimentos agronômicos e florestais: Exposição com exemplos e orientações para uso de aplicativos. Piracicaba: FEALQ, 309p.

Hong, T. D., \& Ellis, R. H. A. (1996). A protocol to determine seed storage behavior. IPGRI Technical Bulletin, Rome, $12,62$.

Liu, R.., Wang, L., Tanveer, M., \& Song, J. (2018). Seed Heteromorphism: An Important Adaptation of Halophytes for Habitat Heterogeneity. Front. Plant Sci., 9, 1515. https://doi.org/10.3389/fpls.2018.01515

Lisboa, R. C. L., \& Ilkiu-Borges, A. L. (1995). Diversidade das briófitas de Belém (PA) e seu potencial como indicadoras de poluição urbana. Bol. Mus. Para. Emilio Goeldi, 11(2), 199-225. https://repositorio.museu-goeldi.br/bitstream/mgoeldi/605/1/B\%20MPEG\%20Bot\%2011\%282\%29\%201995\%20LISBOA.pdf

Maciel, S., Souza, M. G. C., \& Pietrobom, M. R. (2007). Licófitas e monilófitas do Bosque Rodrigues Alves Jardim Botânico da Amazônia, município de Belém, estado do Pará, Brasil. Ciências Naturais, 2(2), 69-83. http://scielo.iec.gov.br/pdf/bmpegcn/v2n2/v2n2a06.pdf

Marcos-Filho, J. (2015). Fisiologia de Sementes de Plantas Cultivadas. Londrina: ABRATES, (2a ed.), 660 p.

Matta, A. A. (2003). Flora médica brasiliense. Editora Valer e Governo do Amazonas, 3(3), 356 p.

Medeiros, M. G., Silva-Neto, J. S. S., Oliveira, G. B. S., Torres, S. B., \& Silveira, L. M. (2019). Physiological maturity of Luffa cylindrica (L.) Roem. Seeds. Revista Ciência Agronômica, 50(1), 76-82. 10.5935/1806-6690.20190009 
Melo, L. A., Abreu, A. H. M., Leles, P. S. S., Oliveira, R. R., \& Silva, D. T. (2018). Qualidade e crescimento inicial de mudas de Mimosa caesalpiniifolia Benth.produzidas em diferentes volumes de recipientes. Ciência Florestal, 28(1), 47-55. DOI: http://dx.doi.org/10.5902/1980509831574

Mendonça, P. M., Lima, M. G., Albuquerque, L. R. M., Carvalho, M. G., Queiroz, M. M. C. (2011). Effects of latex from “Amapazeiro” Parahancornia amapa (Apocynaceae) on blowfly Chrysomya megacephala (Diptera: Calliphoridae) post-embryonic development, Veterinary Parasitology, 178, 379-382. doi: 10.1016 / j.vetpar.2011.01.002

Morais, P. B., Martins, M. C. B., Klaczko, L. B., Hagler, L. C. M., Hagler, A. N. (1995). Yeast Succession in the Amazon Fruit Parahancornia amapa as Resource Partitioning among Drosophila spp. Applied And Environmental Microbiology, $61(12)$, $4251-4257$. https://aem.asm.org/content/aem/61/12/4251.full.pdf

Oliveira-Bento, S. R. S., Torres, S. B., Oliveira, F. N., Paiva, E. P., Bento, D. A. V. (2013). Biometria de frutos e sementes e germinação de Calotropis procera AITON (Apocynaceae), Bioscience Journal, 29(5), 1194-1205. http://www.seer.ufu.br/index.php/biosciencejournal/article/view/22261

Piovesan, P. R. R., Amorim, D. M., Souza, D. V., \& Mello, B. M. (2013). Aspectos biométricos e tecnológicos de sementes de Aspidosperma desmanthum (Apocynaceae), In: $62^{\circ}$ Congresso Nacional de Botânica, Belo Horizonte.

Pinto, J. E. B. P., Santiago, E. J. A., \& Lameira, O. L. (2000). Compêndio de plantas medicinais. UFLA/FAEPE, 205 p.

Popinigis F. (1977). Fisiologia de sementes. AGIPLAN, 289 p.

Salomão, A. N., Santos, I. R. I., \& Mundim, R. C. (2005). Conservação, manejo e uso de sementes Hancornia speciosa Gomez (Apocynaceae), Documentos: Embrapa Recursos Genéticos e Biotecnologia.

Santos, S. R. G., \& Aguia, I. B. (2005). Efeito da temperatura na germinação de sementes de Sebastiania commersoniana (Baillon) Smith \& Downs separadas pela coloração do tegumento, Scientia Forestalis, 69, 77-83. Retrieved from https://www.ipef.br/publicacoes/scientia/nr69/cap06.pdf

Santos, A. C. F., Aguiar-Dias, A. C. A., Amarante, C. B., \& Ferreira, M. C. (2013). Estruturas secretoras da lâmina foliar de amapá amargo (Parahancornia fasciculata, Apocynaceae): histoquímica e dosamento de flavonoides, Revista Acta Amazonica, 43(4), 407-414. http://dx.doi.org/10.1590/S004459672013000400002

Silva, M. S., Fantini, A. C., \& Shanley, P. (2011). Látex de amapá (Parahancornia fasciculata (Poir) Benoist, Apocynaceae): remédio e renda na floresta e na cidade. Ciências Humanas, 6(2), 287-305. http://dx.doi.org/10.1590/S1981-81222011000200003.

Soares, A. N. R., Rocha Júnior, V. F., Vitória, M. F., Silva, A. V. C. (2016). Germinação de sementes de nim em função da maturidade fisiológica e do substrato. Nucleus, 13(1) http://dx.doi.org/10.3738/1982.2278.1601

Venturi. S., \& Randi, A. M. (1997). Influência da coloração das sementes na germinação de Phyllanthus tenellus Roxb. e Phyllanthus niruri L. (Euphorbiaceae). Acta botanica brasilica, 11(1), 87-94. http://dx.doi.org/10.1590/S0102-33061997000100009

Vidal, W. N., \& Vidal, M. R. R. (2003). Botânica-organografia: quadros sinóticos ilustrados de fanerógamos. Universidade Federal de Viçosa, 124 p.

Yuyama, K., \& Silva-Filho, D. F. (2003). Influência do tamanho e da coloração da semente na emergência de plântulas de camu-camu. Revista de Ciências Agrárias, 39:155-162. https://periodicos.ufra.edu.br/index.php/ajaes/article/view/229 